\title{
Brachial Plexus Neuritis
}

National Cancer Institute

\section{Source}

National Cancer Institute. Brachial Plexus Neuritis. NCI Thesaurus. Code C84600.

An inflammatory process affecting the brachial plexus. It results in severe pain in the upper extremity and shoulder, upper arm weakness and loss of sensation in the upper arm. 